\title{
Plaučių arterijos trombinès embolijos gydymas ir profilaktika
}

\author{
Rūta Nutautienè, Skaidrius Miliauskas, Marius Žemaitis \\ LSMU MA Pulmonologijos ir imunologijos klinika
}

Reikšminiai žodžiai: venų tromboembolija, plaučių arterijos trombinè embolija, diagnostikos ir gydymo rekomendacijos.

Santrauka. Plaučių arterijos tromboembolija (PATE) lemia dideli sergamumą ir mirštamumą. Nustačius diagnozę, per 1 mėnesį maždaug 12 proc. PATE atvejų baigiasi mirtimi. JAV per metus nuo PATE miršta apie 600 tūkst. žmonių. Diagnostikai palengvinti ir optimaliai gydymo taktikai numatyti, remiantis $2008 \mathrm{~m}$. Europos kardiologų draugijos paskelbtomis ūminės plaučių arterijos embolijos diagnostikos ir gydymo gairèmis, rekomenduojama naudoti Ženevos ir Velso PATE klinikinės tikimybės vertinimo skales, o iki šiol taikyto PATE skirstymo į masyvią, vidutinę ir nemasyvią siūloma atsisakyti. Vietoje to vertinti su PATE susijusios ankstyvos mirties riziką, kuri nustatoma atsižvelgiant į hemodinamikos stabilumą. Gelbstint pacientų gyvybę, svarbiausia atkurti kraujotaką užsikimšusioje plaučių arterijoje bei užtikrinti tinkamas profilaktikos priemones, kurios sumažintų sergamumą ir mirštamumą nuo PATE komplikacijų.

\section{PATE GYDYMAS}

Ivykus PATE, atsiranda plaučių hemodinamikos, sisteminès kraujotakos ir širdies funkcijos pokyčių. PATE susijusi su ankstyvos mirties rizika. Pagrindinè mirties priežastis - ūminis kraujotakos nepakankamumas, sąlygotas sumažèjusio bendrojo plaučių arterijų ploto bei gretutinių širdies ir plaučių ligų. Bendrieji gydymo principai PATE atvejais: hemodinamikos, kvèpavimo funkcijos koregavimas, nepavèluota trombolizè ir gydymas antikoaguliantais bei chirurginemis intervencijomis.

Esant didelès rizikos PATE, rekomenduojama kaip galima greičiau pradèti trombolizę ir antikoaguliacini gydymą, kad būtų apsaugota nuo dešiniojo skilvelio nepakankamumo progresavimo ir ankstyvos mirties, hipotenzijai koreguoti skiriama vazopresorių. Esant mažam širdies tūriui ir normaliam kraujospūdžiui, galima skirti dobutamino ar dopamino. Intraveninès dobutamino injekcijos pagerina širdies išstūmimo frakciją ir užtikrina deguonies pernašą bei audinių oksigenaciją palaikant pastovu $\mathrm{PO}_{2}$ [1]. Agresyvi infuzijuc terapija AKS koreguoti nerekomenduojama.

PATE atvejais dažnai sumažėja deguonies ir anglies dioksido koncentracijos kraujyje. Kraujo dujų rodikliams pagerinti ir normalizuoti skiriama oksigenoterapija pro nosies kateteri bei retais atvejais taikoma mechaninè ventiliacija. Jeigu vis dèlto pasirenkama mechaninè ventiliacija, rekomenduojami maži ịkvèpimo tūriai (apie $6 \mathrm{ml} / \mathrm{kg}$ ). Teigiamas slègis iškvèpimo pabaigoje (PEEP) didinamas itin atsargiai, o galutinis ịkvėpimo slègis neturi viršyti 30 $\mathrm{cm} \mathrm{H}_{2} \mathrm{O}$ [2].

Didelès rizikos pacientams, kuriems yra kardiogeninis šokas ir (ar) laikosi mažas arterinis kraujospūdis, taikoma trombolizè. Chirurginè embolektomija atliekama pacientams, kuriems trombolizė nepavyko arba yra absoliučiųjų kontraindikacijų ją atlikti. Kateterinè embolektomija arba proksimalinių plaučių arterijų trombų fragmentavimas galimas kaip alternatyva chirurginiam gydymui, kai yra absoliučiųjų kontraindikacijų atlikti trombolizę arba ji nepavyko.

\section{Trombolizè}

Trombolizé yra pirmos eilès gydymo metodas ìvykus PATE ir esant ankstyvos mirties tikimybei (1 lentelè) bei kardiogeniniam šokui ir/ar nuolatiniei arterinei hipotenzijai. Trombolizè netaikytina esant mažai PATE rizikai. Ivertinus atsitiktinių imčių tyrimų [3-9] duomenis, prieita prie išvados, kad trombolizė greitai ir efektyviai pašalina tromboembolinę obstrukciją bei teigiamai veikia hemodinamikos rodiklius. Palyginus trombolizinius preparatus, paaiškejo, kad urokinazès ir streptokinazès 12-24 valandu trukmès infuziju efektyvumas vienodas. Tiesioginè vietinè rekombinantinio audiniuc plazminogeno aktyvatoriaus (rtPA) injekcija i plaučių arteriją pro kateteri veiksmingumu nepranoksta sisteminès intraveninès trombolizès [10]. Trombolizei patvirtinti preparatai (streptokinazè, urokinazè bei rtPA) ir jų dozès pateikti 2 lentelèje.

Trombolizė visada kelia didelę kraujavimo riziką, ypač 
1 lentelè. Rizikos skirstymas pagal ankstyvos mirties riziką PATE atvejais

\begin{tabular}{|c|c|c|c|c|c|}
\hline \multirow{2}{*}{\multicolumn{2}{|c|}{$\begin{array}{l}\text { Su PATE susijusi ankstyvos mirties } \\
\text { rizika }\end{array}$}} & \multicolumn{3}{|l|}{ Rizikos veiksniai } & \multirow[t]{2}{*}{ Galima gydymo taktika } \\
\hline & & $\begin{array}{l}\text { Klinikiniai (šokas } \\
\text { ar hipotenzija) }\end{array}$ & $\begin{array}{l}\text { Dešiniojo skilvelio } \\
\text { disfunkcija }\end{array}$ & $\begin{array}{l}\text { Miokardo pažeidimo } \\
\text { žymenys }\end{array}$ & \\
\hline \multicolumn{2}{|c|}{ Didelè > 15 proc. } & + & $(+)$ & $(+)$ & Trombolizė arba embolektomija \\
\hline \multirow[t]{4}{*}{ Nedidelè } & Vidutinė $3-15$ proc. & - & + & + & Stacionarusis gydymas \\
\hline & & & + & - & \\
\hline & & & - & + & \\
\hline & Maža $<1$ proc. & - & - & - & $\begin{array}{l}\text { Trumpalaikis gydymas arba } \\
\text { ambulatorinis gydymas }\end{array}$ \\
\hline
\end{tabular}

esant skatinamųjų veiksnių ar gretutinių ligų. Prieš pradedant gydymą, visada reikètu ịvertinti pasirinktos gydymo taktikos naudos ir rizikos santykị. 3 lentelejje pateiktas sąrašas būklių, kurioms esant fibrinolizinio gydymo taikyti negalima.

\section{Pradinis gydymas antikoaguliantais}

Antikoaguliaciniai vaistai svarbiausi gydant PATE. Esant nedidelès rizikos PATE, atsižvelgiant ì didelị mirtingumą, gydyti antikoaguliantais pradedama tuoj pat, nelaukiant diagnostinių tyrimų rezultatų. Daugumos pacientuc pradiniam gydymui rekomenduojami mažos molekulinès masès heparinas (MMMH) ar fondaparinuksas. Pacientų, kuriems yra didelè kraujavimo rizika arba ryškus inkstų funkcijos nepakankamumas, pradiniam gydymui rekomenduojamas nefrakcionuotas heparinas (NH) (DATL palaikant 1,5-2,5 didesnị už pradinị) arba fondaparinuksas kartu su vitamino $\mathrm{K}$ antagonistu.

Intraveninių $\mathrm{NH}$ injekcijų dozès parenkamos pagal kūno masę: $80 \mathrm{VV} / \mathrm{kg}$ - smūginè dozè ir po $18 \mathrm{VV} / \mathrm{kg} /$ val. nuolatinei infuzijai [11]. Tolesnis heparino dozavimas turi būti nustatomas pagal dalinio aktyvinto tromboplastino laiko (DATL) rodiklius. Tinkamos dozès parinkimo remiantis DATL rodikliais rekomendacijos pateiktos 4 lentelejje.

$\mathrm{NH}$ ar MMMH gali skatinti trombocitopenijos vystymąsi, todèl labai svarbu gydant stebèti trombocitu koncentraciją kraujyje.

Parenterinių antikoaguliantų skyrimas turi būti nutrauktas, kai TNS pasiekia 2,0-3,0 reikšmę ir toks išlieka dvi paras. Varfarinu pradedama gydyti $5 \mathrm{mg}$ ar 7,5 $\mathrm{mg}$ doze, pirmenybè teikiama didesnei dozei. Tolesnis preparato dozavimas priklauso nuo TNS rodiklių, tikslinè - 2,5 reikšmė (terapinès ribos - nuo 2,0 iki 3,0).

\section{Chirurginiai gydymo metodai}

PATE atvejais plaučių embolektomija taikoma pacientams, kuriems reikalinga kardiopulmoninè reanimacija, bei tiems, kuriems trombolizè kontraindikuotina ar buvo neefektyvi, bei esant atvirai ovaliajai angai ar širdies ertmès trombui [12, 13]. Kraujavimas gali sukelti sunkumų ruošiant pacientą trombolizei, tačiau anksčiau atlikta trombolizè nèra kontraindikacija taikyti chirurginę embolektomiją [14]. Ūminès PATE ištiktiems pacientams, kuriuos ilgą laiką vargina dusulys
2 lentelè. Patvirtintos plaučių embolijos trombolizinio gydymo schemos

\begin{tabular}{|c|c|}
\hline Streptokinazè & $\begin{array}{l}\text { Pradinè dozé }-250000 \mathrm{VV} \text { per } 30 \mathrm{~min} \text {., } \\
\text { po to - } 100000 \mathrm{VV} / \mathrm{val} \text {. per } 12-24 \text { val. } \\
\text { Pagreitintas režimas: } 1,5 \mathrm{mln} \text {. VV per } 2 \text { val. }\end{array}$ \\
\hline Urokinazė & $\begin{array}{l}\text { Pradinè dozė } 4400 \mathrm{VV} / \mathrm{kg} \text { per } 10 \mathrm{~min} \text {., po } \\
\text { to }-4400 \mathrm{VV} / \mathrm{kg} / \mathrm{val} \text {. per per } 12-24 \mathrm{val} \text {. } \\
\text { Pagreitintas režimas: } 3 \mathrm{mln} \text {. VV per } 2 \text { val. }\end{array}$ \\
\hline $\begin{array}{l}\text { rtPA (rekombinanti- } \\
\text { nis audiniu plazmino- } \\
\text { geno aktyvatorius) }\end{array}$ & $\begin{array}{l}100 \mathrm{mg} \text { per } 2 \text { val. arba } 0,6 \mathrm{mg} / \mathrm{kg} \text { per } 15 \\
\text { min. (maksimali doze }-50 \mathrm{mg} \text { ) }\end{array}$ \\
\hline
\end{tabular}

3 lentelè. Fibrinolizinio gydymo kontraindikacijos

\begin{tabular}{|c|c|}
\hline Absoliučiosios kontraindikacijos & Santykinès kontraindikacijos \\
\hline $\begin{array}{l}\text { Hemoraginis ar nežinomos } \\
\text { kilmės insultas } \\
\text { Išeminis insultas per pasta- } \\
\text { ruosius } 6 \text { ménesius } \\
\text { - CNS pažeidimai ar navikai } \\
\text { Neseniai ívykusi didelès } \\
\text { apimties trauma, operacija, } \\
\text { galvos trauma (per pastarą- } \\
\text { sias } 3 \text { savaites) } \\
\text { Kraujavimas iš virškinimo } \\
\text { trakto per pastarąji mėnesi } \\
\text { Kraujavimas }\end{array}$ & 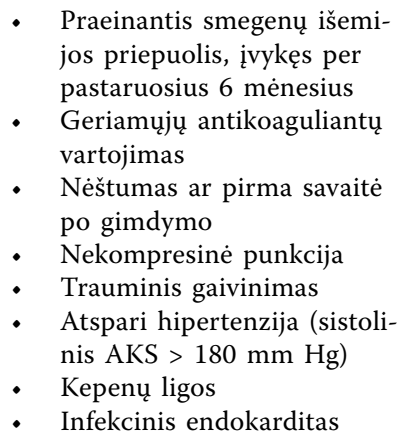 \\
\hline
\end{tabular}

4 lentelè. Intraveninio nefrakcionuoto heparino dozavimas pagal dalinio aktyvinto tromboplastino laiko rodiklius

\begin{tabular}{|c|c|}
\hline DATL reikšmè & Dozès koregavimas \\
\hline$<35 \mathrm{~s}$ (< 1,2 laiko kontrolè) & $\begin{array}{l}80 \mathrm{VV} / \mathrm{kg} \text { smūginè dozė; padidin- } \\
\text { ti infuzijos greiti iki } 4 \mathrm{VV} / \mathrm{kg} / \mathrm{val} \text {. }\end{array}$ \\
\hline $35-45$ s (1,2-1,5 laiko kontrolè) & $\begin{array}{l}40 \mathrm{VV} / \mathrm{kg} \text { smūginè dozė; padidin- } \\
\text { ti infuzijos greiti iki } 2 \mathrm{VV} / \mathrm{kg} / \mathrm{val} \text {. }\end{array}$ \\
\hline 46-70 s (1,5-2,3 laiko kontrolè) & Dozès koreguoti nereikia \\
\hline $71-90 \mathrm{~s}(2,3-3,0$ laiko kontrolè) & $\begin{array}{l}\text { Sumažinti infuzijos greitị iki } \\
2 \mathrm{VV} / \mathrm{kg} / \mathrm{val} \text {. }\end{array}$ \\
\hline > $90 \mathrm{~s}$ (> 3,0 laiko kontrolè) & $\begin{array}{l}\text { Nutraukti infuziją vienai valandai, } \\
\text { paskui sumažinti infuzijos greiti } \\
\text { iki } 3 \mathrm{VV} / \mathrm{kg} / \mathrm{val} \text {. }\end{array}$ \\
\hline
\end{tabular}

ir sunki plaučiu hipertenzija, t. y. lètinè tromboembolinè plaučiuc hiperetenzija, embolektomija kontraindikuotina, todèl pasirenkama specifinè plaučiuc endarterektomija [15]. 
5 lentelè. Emboliją skatinantys veiksniai

\begin{tabular}{|c|c|c|}
\hline Skatinamasis veiksnys & $\begin{array}{l}\text { Paciento } \\
\text { sąlygojamas }\end{array}$ & $\begin{array}{l}\text { Aplinkos } \\
\text { sąlygojamas }\end{array}$ \\
\hline $\begin{array}{l}\text { Didelès rizikos } \\
\text { (patikimumo santykis > 10) } \\
\text { - Lūžis (klubo ar kojos) } \\
\text { - Klubo ar kelio sąnario keitimas } \\
\text { - } \quad \text { Didelès apimties operacija } \\
\text { - Sunki ir didelè trauma } \\
\text { - } \quad \text { Nugaros smegenų sužalojimas }\end{array}$ & & $\begin{array}{l}\checkmark \\
\checkmark \\
\checkmark \\
\checkmark \\
\checkmark\end{array}$ \\
\hline 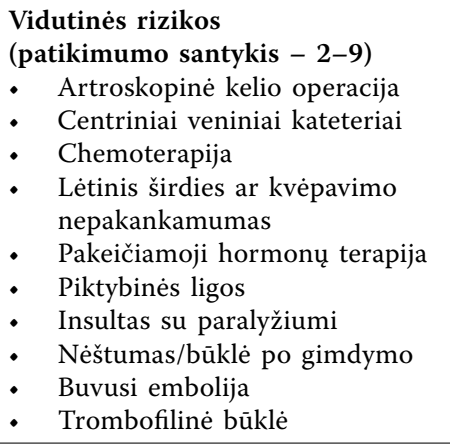 & $\begin{array}{l}\checkmark \\
\checkmark \\
\checkmark \\
\checkmark \\
\checkmark \\
\checkmark\end{array}$ & $\begin{array}{l}\checkmark \\
\checkmark \\
\checkmark\end{array}$ \\
\hline 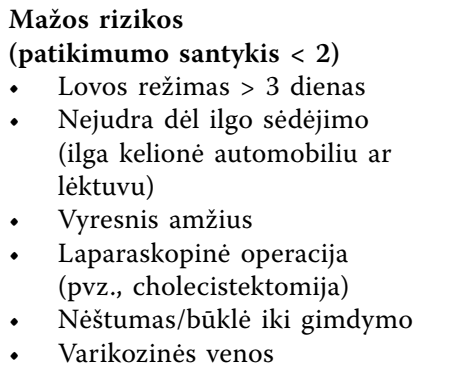 & $\begin{array}{l}\checkmark \\
\checkmark\end{array}$ & $\begin{array}{l}\checkmark \\
\checkmark\end{array}$ \\
\hline
\end{tabular}

6 lentelè. Antrinès profilaktikos trukmè

\begin{tabular}{|c|c|}
\hline $\begin{array}{l}\text { Antrinès profilaktikos } \\
\text { trukmè }\end{array}$ & Indikacija \\
\hline 3 mènesiai & $\begin{array}{l}\text { Embolija sąlygota laikino (grị̌tamojo) } \\
\text { rizikos veiksnio (1 A) } \\
\text { Pirmas izoliuotos idiopatinès GVT } \\
\text { epizodas }(2 \mathrm{~B})\end{array}$ \\
\hline $\begin{array}{l}\text { Ne mažiau kaip } 3 \\
\text { menesiai }\end{array}$ & $\begin{array}{l}\text { Idiopatinè PATE }(1 \mathrm{~A}) \text { (jei kraujavimo } \\
\text { rizika maža ir yra galimybè užtikrinti ir } \\
\text { palaikyti stabilią antikoaguliaciją - spręsti } \\
\text { dèl ilgalaikio gydymo krešejjimo sistemą } \\
\text { veikiančiais vaistais }(1 \mathrm{C}) \text { ) }\end{array}$ \\
\hline Ilgalaikè & $\begin{array}{l}\text { Antras idiopatinès PATE epizodas }(1 \mathrm{~A}) \\
\text { PATE sergant vėžiu: MMMH pirmuosius } \\
3-6 \text { menesius }(1 \mathrm{~A}) \text {; veliau galima pereiti } \\
\text { prie gydymo vitamino } \mathrm{K} \text { antagonistais } \\
\text { arba tęsti MMMH neribotą laiką arba kol } \\
\text { bus išgydytas vėžys }(1 \mathrm{C})\end{array}$ \\
\hline
\end{tabular}

Taikant perkutaninę embolektomiją, atveriamas iš dalies užsikimšęs plaučių kamienas ar pagrindinė plaučiuc arterija, ir taip išgelbejjama gyvybè esant kritinei būklei dèl dideles PATE rizikos $[16,17]$. Perkutaninè kateterinè embolektomija gali būti taikoma kaip alternatyva trombolizei, kai yra absoliučiųjų kontraindikacijų ją atlikti ar kai ji buvo neefektyvi.

\section{ANTRINĖ PATE PROFILAKTIKA}

Populiacijos tyrimų duomenimis, pacientams, kuriems jau kartą pasireiškè trombinè embolija, jos kartojimosi rizika yra didesnè [19]. Pasikartojimo rizika priklauso nuo laiko - dažniausia ji per pirmuosius 6-12 mènesių po pirmojo epizodo. Taigi kartotinès trombinès embolijos dažnumas - apie 10 proc. per pirmuosius 6 mènesius, 12 proc. - per pirmuosius metus, 25 proc. - per 5 metus ir 30 proc. - per 10 metú.

Kaip ir ūminè embolija, kartotiné trombinè embolija ženkliai didina sergamumą ir mirštamumą. Pasikartojus PATE, miršta apie 49 proc. pacientų [19]. Kartotinè embolija irgi sąlygoja lètinę plautinę hipertenziją. Nepaisant padidejusios trombinès embolijos kartojimosi rizikos, didžiajai daliai pacientu po pirmojo epizodo ji gali daugiau nepasireikšti. Susumavus tyrimų duomenis, nustatyta, jog apie 70 proc. pacientu per 10 metu po pirmojo epizodo embolija nepasikartojo. Todèl itin svarbu atrinkti didelès rizikos pacientus, kuriems yra skatinamuju rizikos veiksnių (5 lentelè) ir trombinès embolijos kartojimosi rizika, - tuos, kuriems ilgalaikè antrinè profilaktika antikoaguliaciniais vaistais būtų naudingiausia [19].

Neskyrus profilaktikos antikoaguliantais per pirmuosius 3 ménesius po pirmojo PATE epizodo, embolija pasikartojo 50 proc. pacientuc [18].

Onkologiniams ligoniams, net ir gydomiems antikoaguliantais, kartotinès embolijos rizika didesnè 2-4 kartus, palyginti su věžiu nesergančiais pacientais. Toliau rizika auga didejjant piktybiškumui bei pradejjus taikyti chemoterapiją. Tokiems pacientams kartotinès embolijos rizika gali siekti 50-67 proc., ypač per pirmuosius mėnesius po antikoaguliantų vartojimo nutraukimo [19].

Kai pacientas antikoaguliantais nebegydomas, jo būklei stebèti bei kartotinei embolijai nustatyti siūloma tirti D dimerus, liekamąją venų trombozę ultragarsiniu tyrimu (GVT atveju) bei trombino gamybą (jo tyrimas dar nestandartizuotas, bet manoma, jog jis gali padèti numatyti embolijos kartojimąsi) [20].

Ivertinus anksčiau aptartus rizikos veiksnius bei laboratorinius parametrus, sprendžiama dèl antrinès profilaktikos trukmès (6 lentelè) [19]. Būtina atsižvelgti i kartotinès embolijos riziką neskyrus gydymo bei antikoaguliantų sąlygojamo kraujavimo riziką [21]. Persirgusiųjų PATE ilgalaikio gydymo tikslas - apsaugoti nuo mirtinu ir nemirtinų kartotinès embolijos atvejų [18].

\section{Kraujavimo rizika gydant antikoaguliantais}

Kraujavimo rizika didžiausia pirmaisiais antikoaguliantų vartojimo ménesiais (nes pradejus antikoaguliacini gydymą dažniausiai ima kraujuoti esami pažeidimai, pvz., opos). Vèliau kraujavimo rizika ima mažèti (metaanalizès duomenys; dalyvavo pacientai, vartoję antikoaguliantuc ne trumpiau kaip 3 ménesius) [19]. Sergant véžiu, kraujavimo rizika padidèja 4 kartus (dažniausiai dèl paties auglio sukeliamų kraujagyslių pažeidimų bei ligoniams pasireiškiančios trombocitopenijos bei kitų koaguliacijos sutrikimų). 
Kraujavimo rizikai gydant antikoaguliantais įvertinti sukurta įvairiuc skalių. JAV siūloma vadovautis RIETE kraujavimo įvertinimo skale (angl. Registry Bleeding Score), parengta ịvertinus didžiojo kraujavimo riziką tiriant beveik 20 tūkst. pacientų, sirgusių ūmine embolija ir vartojusių antikoaguliantų 3 ménesius (7 lentelè) [19].

\section{Kraujo krešejjimą lètinantys vaistai, vartojami antrinei profilaktikai}

Vitamino K antagonistai (VKA) slopina vèlyvąją nuo vitamino K priklausomų koaguliacijos faktorių, protrombino (ar II faktoriaus), VII, IX bei X faktorių sintezès fazę kepenyse. VKA preparatu skilimo pusperiodis gali būti trumpas (acenokumarolis), vidutinis (varfarinas, fluindionas) ar ilgas (fenprokumonas) [21]. Pastaruosius 6 dešimtmečius daugiausiai vartojamas ir daugeliui pacientų veiksmingas (išskyrus sergančius vėžiu) yra varfarinas. Vartojant ši preparatą būtina reguliariai ir nuolat stebėti paciento būklę ir koreguoti vaisto dozę (norint palaikyti tinkamą gydomąji poveikit) $[19,21]$.

MMMH (enoksiparinas, dalteparinas, nadroparinas, tinzaparinas, bemiparinas) sudaro kompleksus su antitrombinu ir taip netiesiogiai slopina trombiną. MMMH ir antitrombino kompleksai katalizuoja $\mathrm{X}$ a faktoriaus inaktyvaciją; mažiau gaminasi II a faktoriaus (trombino). Visi MMMH gaminami iš NFH naudojant ịvairius jo molekulès depolimerizacijos būdus, todèl jų farmakodinamikos savybès skiriasi. Mažos molekulinès masès heparinai yra panašūs, bet ne identiški. Ši aplinkybè riboja vieno MMMH keitimą kitu, nes, nepaisant keitimo taisyklių, galima sukelti nepageidaujamų komplikacijų (retrombozè, kraujavimas, staigi mirtis) [21].

Palyginti su varfarinu, MMMH pasižymi stabiliu antikoaguliaciniu poveikiu, prognozuojamu atsaku bei nuspejjama vaistų sąveika, greita veikimo pradžia; nereikia nuolat tikrinti poveikio krešejjimui.

Varfarino ir MMMH trūkumai paskatino naujųjų geriamųjų antikoaguliantų, veikiančių tik vieną aktyvų krešejjimo faktorių (pvz., trombiną ar Xa faktorių), paieškas. Trečios fazès klinikiniai tyrimai atlikti tik su trimis vaistais: dabigatrano eteksilatu, apiksabanu ir rivaroksabanu (8 lentelè) [22].
2008 metuc Europos Komisija patvirtino naujajj geriamąji antikoaguliantą dabigatraną eteksilatą trombinès embolijos profilaktikai po ortopedinių operacijų. Šių metu pradžioje antrinei trombinès embolijos profilaktikai patvirtintas ir rivaroksabanas.

Rivaroksabanas - tai tiesioginis $\mathrm{X}$ a faktoriaus inhibitorius, selektyviai ir grịžtamai slopinantis tiek laisvojo, tiek krešulyje esančio $X$ a faktoriaus bei protrombinkinazès aktyvumą. Vaistas pasižymi dideliu bioprieinamumu bei greita veikimo pradžia.

Rivaroksabano efektyvumas ir saugumas antrinei embolijos profilaktikai buvo vertinamas EINSTEINEXT tyrime; jo rezultatai pristatyti 2009 m. Šiame placebu kontroliuojamame dvigubai aklame tyrime skirta $20 \mathrm{mg}$ rivaroksabano kasdien dar 6-12 mėnesių pacientams, kurie jau buvo gydyti VKA 6-12 ménesių nuo ūminès embolijos [19]. Pacientai, kuriems indikacijos tęsti antikoaguliacinị gydymą buvo aiškios, ị tyrimą neittraukti. Pagrindinis efektyvumo kriterijus - simptominès embolijos (GVT, nemirtinos PATE ir mirtinos PATE) pasikartojimas, o pirminis saugumo kriterijus - kraujavimas. Ne didžiojo kraujavimo (pvz., iš nosies, didelès hematomos odoje, makroskopinè hematurija) atvejų dažnumas buvo antrinis saugumo kriterijus. Po gydymo vidutiniškai 190 dienų simptominė kartotinè embolija ištiko 1,3 proc. rivaroksabanu gydytų paci-

\begin{tabular}{|c|c|}
\hline Rizikos veiksniai & Balai \\
\hline Neseniai buvęs masyvus kraujavimas & 2 \\
\hline Kreatinino kiekis $>110 \mu \mathrm{mol} / \mathrm{l}$ & 1,5 \\
\hline $\begin{array}{l}\text { Anemija: } \\
\text { - Hb moterims } 120 \mathrm{~g} / \mathrm{l} \\
\text { - } \quad \text { Hb vyrams } 130 \mathrm{~g} / \mathrm{l}\end{array}$ & 1,5 \\
\hline Vèžys & 1 \\
\hline Kliniškai pasireiškianti PATE & 1 \\
\hline Amžius > 75 metų & 1 \\
\hline
\end{tabular}

8 lentelè. Antrinès profilaktikos trečios fazès klinikiniai tyrimai (tęstiniai)

\begin{tabular}{|c|c|c|c|c|}
\hline Tyrimas (tebevyksta) & $\begin{array}{l}\text { Tiriamas geriamasis } \\
\text { preparatas }\end{array}$ & Lyginamasis preparatas & Tiriamųjų skaičius & Gydymo trukmè \\
\hline RE-MEDY & $\begin{array}{l}\text { Dabigatrano eteksilatas } \\
150 \text { mg } 2 \text { kartus }\end{array}$ & $\begin{array}{l}\text { Varfarinas (TNS }-2,0-3,0 \text { ); prieš atsitikti- } \\
\text { nę atranką visi pacientai } 3-6 \text { mèn. gydyti } \\
\text { antikoaguliantais nuo ūminès embolijos }\end{array}$ & 2700 & 18 mèn. \\
\hline RE-SONATE & $\begin{array}{l}\text { Dabigatrano eteksilatas } \\
150 \text { mg } 2 \text { kartus }\end{array}$ & $\begin{array}{l}\text { Placebas; prieš atsitiktinę atranką visi pa- } \\
\text { cientai } 6-18 \text { mèn. gydyti antikoaguliantais } \\
\text { nuo ūminès embolijos }\end{array}$ & 1462 & 6 mèn. \\
\hline AMPLIFY-EXT & $\begin{array}{l}\text { Apiksabanas } \\
2,5 \mathrm{mg} 2 \text { kartus } \\
5,0 \mathrm{mg} 2 \text { kartus }\end{array}$ & $\begin{array}{l}\text { Placebas; prieš atsitiktinę atranką visiems } \\
\text { pacientams buvo baigtas planuotas gydy- } \\
\text { mas nuo ūminès embolijos }\end{array}$ & 2430 & 12 mèn. \\
\hline EINSTEIN-EXT (baigtas) & $\begin{array}{l}\text { Rivaroksabanas } \\
20 \mathrm{mg} \text { kasdien }\end{array}$ & $\begin{array}{l}\text { Placebas; prieš atsitiktinę atranką visi pa- } \\
\text { cientai } 6-12 \text { mèn. gydyti antikoaguliantais } \\
\text { nuo ūminès simptominès embolijos }\end{array}$ & 1197 & 6-12 mèn. \\
\hline
\end{tabular}


entų, palyginti su 7,1 proc. vartojusių placebą, o tai rodo ženklų santykinès rizikos sumažejjimą rivaroksabano grupèje [19]. Kraujavimo dažnumas buvo kur kas didesnis rivaroksabano grupeje; didžiojo kraujavimo atveju $-0,7$ proc. rivaroksabano grupeje, palyginti su 0 proc. placebo grupejje; tiesa, nebuvo nè vieno mirtino ar kritinio kraujavimo atvejo. Kliniškai reikšmingo ne didžiojo kraujavimo dažnumas rivaroksabano grupèje buvo 5,4 proc., placebo - 1,2 proc. [19].

\section{APIBENDRINIMAS}

PATE atvejais rekomenduojama gydymą pradèti nuo parenteriniu antikoaguliantuc (MMMH, fondaparinuksas, intraveniniai arba poodiniai nefrakcionuoto heparino preparatai). Pacientams, priklausantiems didelès PATE rizikos grupei, gydymą antikoaguliantais rekomenduojama pradèti, kol laukiama diagnostinių tyrimų rezultatų, o vidutinès rizikos pacientams - jeigu diagnostinių tyrimų rezultatai paaiškès vèliau nei po 4 valandų. Mažos rizikos asmenims gydymas antikoaguliantais nerekomenduojamas. Ūminès plaučiuc embolijos atveju rekomenduojama kuo anksčiau skirti VKA ir tęsti gydymą parenteriniais antikoaguliantais ne mažiau kaip 5 paras palaikant TNS 2,0. Esant ūminei plaučiuc embolijai skiriama parenterinių antikoaguliantų (MMMH (vieną kartą per parą), fondaparinuksas, intraveniniai arba poodiniai nefrakcionuoto heparino preparatai). Jei plaučių emboliją lydi hipotenzija ir kraujavimo rizika didelè, pasirenkamas sisteminis trombolizinis gydymas.

Kaip ir ūminè embolija, kartotinè trombinè embolija irgi ženkliai didina sergamumą ir mirštamumą. Taigi itin svarbu atrinkti didelès rizikos pacientus, kuriems yra skatinamųju rizikos veiksnių ir trombinès embolijos kartojimosi rizika, - tuos, kuriems ilgalaikè antriné profilaktika antikoaguliaciniais vaistais būtų naudingiausia.

\section{TREATMENT AND PREVENTION OF PULMONARY EMBOLISM}

\section{RŪTA NUTAUTIENĖ, SKAIDRIUS MILIAUSKAS, MARIUS ŽEMAITIS DEPARTAMENT OF PULMONOLOGY AND IMMUNOLOGY LITHUANIAN UNIVERSITY OF HEALTH SCIENCES}

Keywords: venous thromboembolism, pulmonary thromboembolism, guidelines for diagnosis and treatment.

Summary. Of pulmonary embolism associated with high morbidity and mortality. Diagnosis within one month of around 12 percent. cases of pulmonary embolism resulting in death. U.S. during the years of the pulmonary die about 600 thousand. people. For easier diagnostic issues and choosing the most efective treatment strategies, guidelines for diagnosis and management of acute pulmonary embolism published in 2008 by European Society of Cardiology, were presented to use Geneva and Wells scores for assessment of clinical probability of PE. Current guidelines suggest replacing terms such as "massive, sub-massive, non-massive" with the estimated levels of risk of PE-related early death, witch is determined according to patients haemodynamic stability. he primarily aim in haemodynamicly unstable patients is urgent restoration of the low through occluded pulmonary arteries, with potentially life-saving efects.

\section{LITERATŪRA}

1. Manier G, Castaing Y. Influence of cardiac output on oxygen exchange in acute pulmonary embolism. Am Rev Respir Dis 1992; 145: 130-136.

2. Goldhaber SZ, Haire WD, Feldstein ML, Miller M, Toltzis R, Smith JL et al. Alteplase versus heparin in acute pulmonary embolism: randomised trial assessing rightventricular function and pulmonary perfusion. Lancet 1993; 341: 507-511.

3. Ly B, Arnesen $\mathrm{H}$, Eie $\mathrm{H}, \mathrm{Hol}$ R. A controlled clinical trial of streptokinase and heparin in the treatment of major pulmonary embolism. Acta Med Scand 1978; 203: 465-470.

4. Daniels LB, Parker JA, Patel SR, Grodstein F, Goldhaber SZ. Relation of duration of symptoms with response to thrombolytic therapy in pulmonary embolism. Am J Cardiol 1997; 80: 184-188.

5. Yalamanchili K, Fleisher AG, Lehrman SG, Axelrod HI, Lafaro RJ, Sarabu MR et al. Open pulmonary embolectomy for treatment of major pulmonary embolism. Ann Thorac Surg 2004; 77: 819-823.

6. Leacche M, Unic D, Goldhaber SZ, Rawn JD, Aranki SF, Couper GS et al. Modern surgical treatment of massive pulmonary embolism: results in 47 consecutive patients after rapid diagnosis and aggressive surgical approach. J Thorac Cardiovasc Surg 2005; 129: 1018-1023.

7. Aklog L, Williams CS, Byrne JG, Goldhaber SZ. Acute pulmonary embolec tomy: a contemporary approach. Circulation 2002; 105: 1416-1419.

8. Hoeper MM, Mayer E, Simonneau G, Rubin LJ. Chronic thromboembolic pulmonary hypertension. Circulation 2006; 113: 2011.

9. Brady AJ, Crake T, Oakley CM. Percutaneous catheter fragmentation and dista dispersion of proximal pulmonary embolus. Lancet 1991; 338: 1186-1189.

10. Schulman S, Rhedin AS, Lindmarker P, Carlsson A, Larfars G, Nicol P et al. A comparison of six weeks with six months of oral anticoagulant therapy after a first episode of venous thromboembolism. Duration of Anticoagulation Trial Study Group. N Engl J Med 1995; 332: 1661-1665.

11. Raschke RA, Gollihare B, Peirce JC. The effectiveness of implementing the weight-based heparin nomogram as a practice guideline. Arch Intern Med 1996; 156: 1645-1649.
12. Yalamanchili K, Fleisher AG, Lehrman SG, Axelrod HI, Lafaro RJ, Sarabu MR et al. Open pulmonary embolectomy for treatment of major pulmonary embolism. Ann Thorac Surg 2004; 77: 819-823.

13. Leacche M, Unic D, Goldhaber SZ, Rawn JD, Aranki SF, Couper GS et al Modern surgical treatment of massive pulmonary embolism: results in 47 consecutive patients after rapid diagnosis and aggressive surgical approach. J Thorac Cardiovasc Surg 2005; 129: 1018-1023.

14. Aklog L, Williams CS, Byrne JG, Goldhaber SZ. Acute pulmonary embolectomy: a contemporary approach. Circulation 2002; 105: 1416-1419.

15. Hoeper MM, Mayer E, Simonneau G, Rubin LJ. Chronic thromboembolic pulmonary hypertension. Circulation 2006; 113: 2011-2020.

16. Brady AJ, Crake T, Oakley CM. Percutaneous catheter fragmentation and distal dispersion of proximal pulmonary embolus. Lancet 1991; 338: 1186-1189.

17. Timsit JF, Reynaud P, Meyer G, Sors H. Pulmonary embolectomy by catheter device in massive pulmonary embolism. Chest 1991; 100: 655-658.

18. Torbicki A, Perrier A, Konstantinides S, Agnelli G, Galie N, Pruszczyk P et al. Guidelines on the Diagnosis and Management of Acute Pulmonary Embolism.The Task Force for the Diagnosis and Management of Acute Pulmonary Embolism of the European Society of Cardiology (ESC). Eur Heart J 2008: 29; 2276-2315 - doi:10.1093/eurheartj/ehn310

19. Alexander G, Turpie G. Secondary Prevention of Venous Thromboembolism: Current Controversies and Emerging Therapies; 03/10/2010 http:// cme.medscape.com/viewarticle/716053? src $=0$ mp cmenl_0\&uac $=89126 \mathrm{CX}$

20. Hron G, Kollars M, Binder BR, Eichinger S, Kyrle PA. Identification of patients at low risk for recurrent venous thromboembolism by measuring thrombin generation. JAMA. 2006; 296: 397-402.

21. Schulman S. Current strategies in prophylaxis and treatment of venous thromboembolism. Ann Med. 2008; 40: 352-359.

22. Nishio H, leko M, Nakabayashi T. New therapeutic option for thromboembolism-dabigatran etexilate. Expert Opin Pharmacother. 2008; 9 ; 2509-2517. 